\title{
3D reflection seismic imaging for open-pit mine planning and deep exploration in the Kevitsa Ni-Cu-PGE deposit, northern Finland
}

\author{
Alireza Malehmir ${ }^{1}$, Christopher Juhlin ${ }^{1}$, Chris Wijns ${ }^{2}$, Milovan Urosevic ${ }^{3}$, Petri Valasti $^{2}$, and \\ Emilia Koivisto ${ }^{4}$
}

\begin{abstract}
A 3D reflection seismic survey was conducted over an area of about $9 \mathrm{~km}^{2}$ at the Kevitsa Ni-Cu-PGE (platinum group elements) orebody, northern Finland, where open-pit mining started in mid-2012. The principal objective of the survey was to image major fault and fracture zones at depth that may have an impact on the mine stability and safety. Mine planning would then take into account the geometry of these zones at Kevitsa. Processing results, using conventional prestack DMO and poststack migration methods, show gently dipping and steeply dipping reflections from depths of approximately $2 \mathrm{~km}$ to as shallow as $150-200 \mathrm{~m}$. Many of the reflections are interpreted to originate from either fault systems or internal magmatic layering
\end{abstract}

within the Kevitsa main intrusion. Further correlation between the surface seismic data and VSP data suggests that numerous faults are present in the imaged volume based upon time shifts or phase changes along horizontal to gently dipping reflections. Some of these faults cross the planned open-pit mine at depths of about 300-500 m, and are therefore critical for geotechnical planning. In terms of in-pit and near-mine exploration, the magmatic layering internal to the intrusion controls the distribution of the bulk of economic mineralization. The ability to image this magmatic layering could therefore guide future drilling, particularly by constraining the presumed lateral extents of the resource area. Exploration also will target discrete reflectors that potentially represent higher-grade sulfide mineralization.

\section{INTRODUCTION}

Better mining technology, coupled with the realization that outcropping or shallow deposits are becoming rarer, has led the exploration industry to look ever-deeper in the search for economic mineralization. Conventional geochemical and geophysical methods are less effective in these cases. Most geophysical methods that can penetrate to sufficient depth lack the necessary resolution to effectively complement drilling. Seismic surveys are one of the few methods that do have sufficient resolution at depth to constrain geologic models of an ore deposit at the drilling scale. Reflection seismic methods can be used to partly reduce the drilling cost by focusing the drilling in key or strategically important areas. Although a series of studies are currently being conducted, there are not many published accounts on the use of 3D reflection seismic methods for the purpose of deep mine planning in the crystalline environment, especially in Europe. Three-dimensional reflection seismic methods have been used in South Africa with encouraging results, allowing imaging of fault systems that in turn control the geometry of the ore horizon (Pretorius et al., 2003; Stevenson et al., 2003). To our knowledge, there is no 3D reflection seismic survey conducted for deep open-pit mine planning. Three- and twodimensional reflection seismic surveys have, however, been used for the exploration of deep-seated mineral deposits with several examples from Canada, South Africa, Europe, and Australia (e.g., Milkereit et al., 1996, 2000; Salisbury et al., 2000; Adam et al., 2003; Pretorius et al., 2003; Malehmir et al., 2007, 2009a, 2009b, 2011; Harrison and Urosevic, 2009; Malehmir and Bellefleur, 2009, 2010; Dehghannejad et al., 2010, 2012; Cheraghi et al., 2011; Juhojuntti et al., 2012).

\footnotetext{
Manuscript received by the Editor 24 November 2011; revised manuscript received 14 March 2012 ; published online 7 September 2012.

${ }^{1}$ Uppsala University, Department of Earth Sciences, Uppsala, Sweden. E-mail: alireza.malehmir@geo.uu.se; chrisopher.juhlin@geo.uu.se.

${ }^{2}$ First Quantum Minerals Ltd., Perth, Australia. E-mail: chris.wijns@fqml.com; petri.valasti@fqml.com.

${ }^{3}$ Curtin University, Department of Exploration Geophysics, Perth, Australia. E-mail: m.urosevic@ curtin.edu.au.

${ }^{4}$ University of Helsinki, Department of Geosciences and Geography, Institute of Seismology, Helsinki, Finland. E-mail: emilia.koivisto@helsinki.fi.

(C) 2012 Society of Exploration Geophysicists. All rights reserved.
} 
Kevitsa, our study area, is a large nickel/copper deposit hosted by a massive ultramafic intrusion in northern Finland (Figure 1) with measured and indicated resources of 240 million tons (using a nickel cutoff grade of $0.1 \%$ ) grading $0.30 \%$ nickel and $0.41 \%$ copper. Mining is planned to start with an open-pit that will extend down to a depth of about $550 \mathrm{~m}$. The stripping ratio is expected to be in the order of $4: 1$ and the mine life is expected to be about 20-30 years with operations starting in 2012. Because the pit walls will be steep due to economic and environmental restrictions, it is important that geologic structures transecting the open pit, especially those subparallel to the pit walls, are well understood and mapped in the subsurface. An extensive number of drillholes suggest that the geology of the ore and its host rock is simple with only a few shear zones intersecting the planned open pit. As will be shown later in this paper, the seismic data, on the other hand, suggest numerous faults.

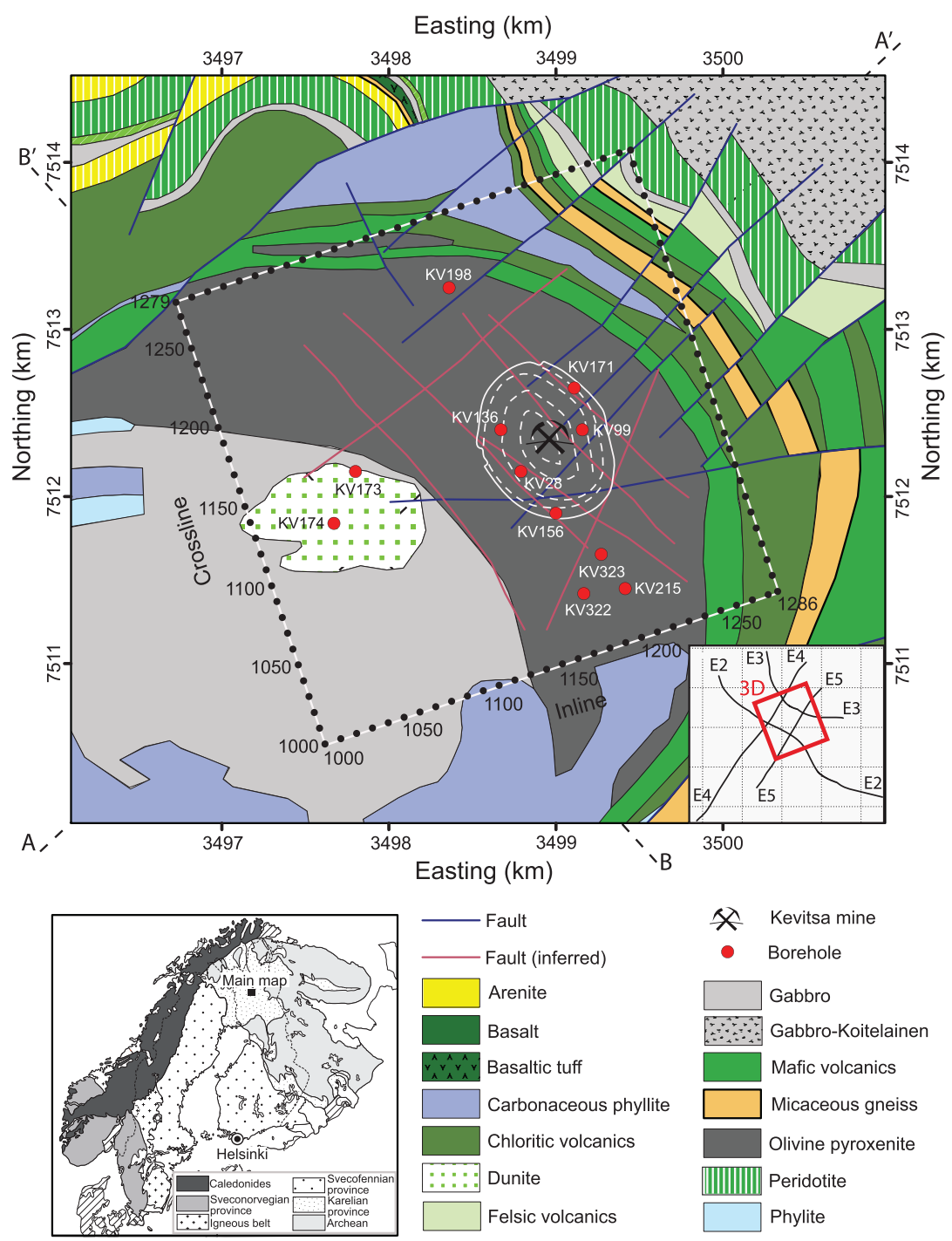

Figure 1. Geologic map (modified from GTK) of the Kevitsa Ni-Cu-PGE deposit, showing the location of the 3D survey (boxed area), deep boreholes in the area and inline and crossline numbers used in this paper. White lines show the location of the planned openpit mine, and its extension. Inset map shows locations of existing 2D profiles (see Koivitso et al., 2012) relative to the 3D survey area. Dashed lines (A-A' and B-B') outside the map show approximate directions of the geologic cross sections shown in Figure 2.
The 3D reflection seismic survey conducted over the Kevitsa deposit already referenced above had two main objectives. The first, encouraged by results from preexisting $2 \mathrm{D}$ reflection lines over the host intrusion (Koivisto et al., 2012), was to evaluate the capability of $3 \mathrm{D}$ reflection seismic methods to image fracture and fault systems around the Kevitsa pit at a resolution sufficient for designing the final geometry of the open pit, especially in terms of assuring slope stability. The second objective was to identify new target areas for exploration of Ni-PGE and base-metal mineralization within or adjacent to the existing resource area. The main imaging challenges encountered with the current data set are highly variable $\mathrm{P}$-wave velocities (maximum velocity is more than $7500 \mathrm{~m} / \mathrm{s}$ ) for the main lithological units and varying near-surface conditions due to varying weather conditions during the data acquisition, from frozen ground at about $-20^{\circ} \mathrm{C}$ in February to a muddy surface at about $+5^{\circ} \mathrm{C}$ at the end of the seismic survey in April. Despite these challenges, processing results show several gently-to-moderately dipping reflections in the data, some of which cross the planned open-pit mine. At larger scales, reflectivity patterns can be used to classify different geologic domains that can guide mineral exploration in the area. In terms of exploration, discrete highamplitude reflections will be used to target massive sulfide mineralization, of which a few occurrences have been found by deep drilling to about $1.1 \mathrm{~km}$ near the margins of the Kevitsa intrusion.

\section{KEVITSA DEPOSIT AND GENERAL GEOLOGY}

The bedrock in the area of the Kevitsa deposit generally consists of Paleoproterozoic basement gneisses, greenstone belts, and major igneous intrusions. At about $2.05 \mathrm{Ga}$, igneous activity generated a series of layered intrusions, one of which hosts the Kevitsa deposit (Mutanen, 1997). The Kevitsa intrusion has an oval shape and is oriented northeast-southwest with a long axis of $7 \mathrm{~km}$ (Figure 2). It is comprised of mafic to ultramafic rocks, including olivine pyroxenite (Kevitsa main intrusion), peridotite, gabbro, and granophyre. The mineralized area of the intrusion is characterized by internal layering defined by changes in composition resulting from successive pulses of magma and not simple differentiation of a single pulse. Clear fault (reverse and normal) and fold structures are evident in the surrounding metasedimentary and layered felsic and mafic volcanic rocks (Figure 2). However, within the main intrusion itself, faults and fracture zones are mainly inferred from potential field data, such as magnetic and gravity data.

Mineralization in the Kevitsa deposit occurs within an olivine-pyroxenite zone in the main intrusion, which contains up to $5 \%$ sulfide, most of which is found as granular masses interstitial to the silicate mineral crystals. The silicate mineralogy is predominantly composed of olivine and orthopyroxene with finely disseminated 
sulfides. The sulfides are comprised mainly of pyrrhotite, pentlandite, chalcopyrite, and various platinum group minerals of lesser volumetric or economic significance. Other copper and nickel sulfides include cubanite, millerite, and heazlewoodite, with minor associated gold, cobalt, and PGE concentrations (KMOY geologists, personal communication, 2010). Although there is no direct evidence that the Kevitsa mineralization is structurally controlled, the Ni-PGE mineralization appears within northwest-southeast to northeast-southwest trending shear zones (Figure 1). Important types of mineralization in the study area include contact-related and possibly remobilized types (usually massive to semimassive, occurring at or below the contact with the intrusion), false types (usually disseminated, dominated by pyrrhotite, and occurring at the margins of the intrusion) and normal types (which are rich in nickel and occur within the intrusion where a magmatic stratigraphy is present). Figure 3 shows a schematic geologic cross section through the Kevitsa intrusion, not strongly constrained by borehole data, illustrating the different types of mineralization proven to exist in the area.

\section{DATA ACQUISITION}

Prior to the 3D data acquisition, the Geological Survey of Finland (GTK), through a nationwide seismic program, the HIRE project (Kukkonen et al., 2011), acquired four short (each about 6-11 km long) high-resolution seismic profiles (see also Koivisto et al., 2012). The 2D seismic profiles successfully imaged the main structures of the Kevitsa intrusion. To image the more shallow $(<1 \mathrm{~km})$ structures in the resource area for mine planning and potentially to find new targets for detailed exploration and increasing the mine life, a 3D seismic survey was conducted over an area of about $9 \mathrm{~km}^{2}$ in winter 2010. Two recording systems (a Seistronix, operated by HiSeis and a Sercel 408, operated by Uppsala University), with a joint capability of recording of up to 1000 channels, were used to record data from nearly 3000 source points that were activated using mainly a mechanical hammer (e.g., Dehghannejad et al., 2010; Juhlin et al., 2010; Malehmir et al., 2011), but also explosives in some locations. The entire 3D acquisition took place in about three months with near-surface conditions changing from frozen ground with a thick layer of snow (up to about $1 \mathrm{~m}$ ) in February to a muddy surface in April. Geophones were placed into the frozen ground or compacted snow resulting in excellent coupling and signal quality. Various tests were conducted during the survey to determine the optimum way of planting the geophones. For example, these tests showed that there was no significant difference in the signal quality for those geophones planted into the

a)

b) frozen ground and those into the compacted snow. Therefore, the seismic crews were advised to plant the geophones in either way depending on the ground conditions and snow thickness.

For the mechanical source, each shot point consisted of three sweeps which were decoded and vertically stacked together during the data processing to increase the signal-to-noise ratio $(\mathrm{S} / \mathrm{N})(\mathrm{e} . \mathrm{g}$., Park et al., 1996). The sampling rate was set $1 \mathrm{~ms}$ for the Sercel 408
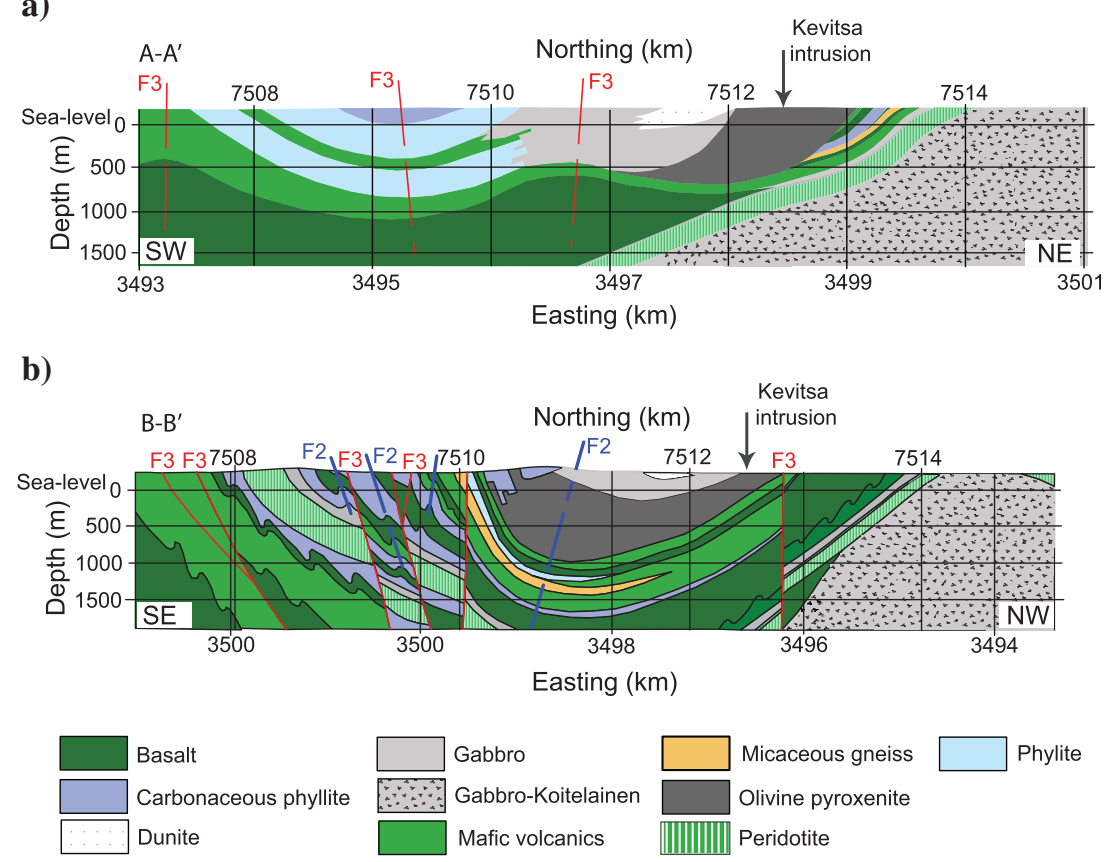

Figure 2. Simplified geologic cross sections along (a) northeast-southwest and (b) southeast-northwest directions, showing expected geometry of the main Kevitsa intrusion (an oval shaped intrusion flattening toward the southwest) and fault systems (courtesy of First Quantum Minerals Ltd.). The geologic cross sections are longer than the geologic map shown in Figure 1.

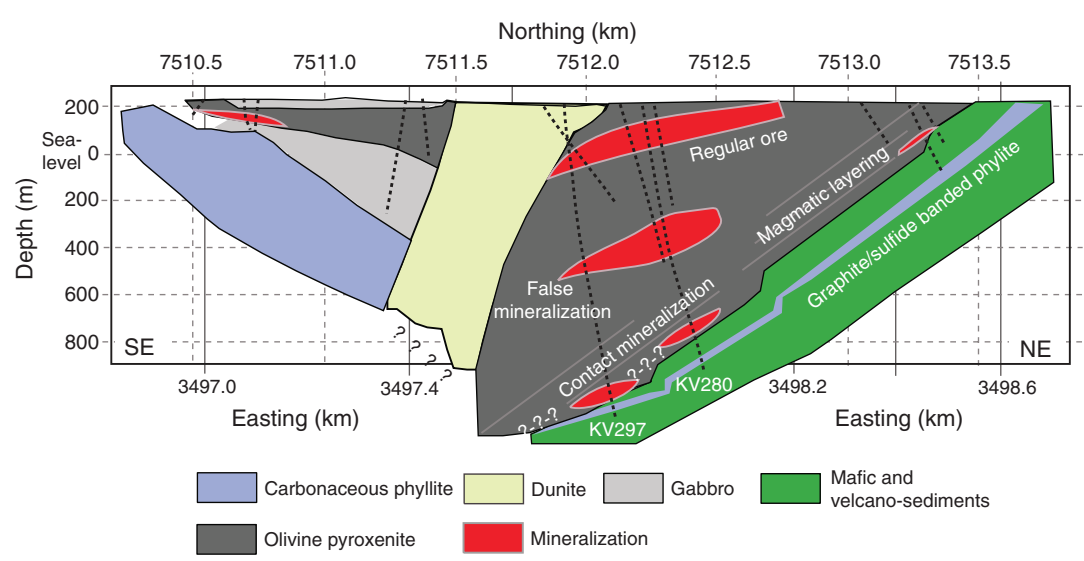

Figure 3. Schematic cross section constrained by deep magnetotelluric and borehole data, showing the main Kevitsa intrusion (hosting the main mineralization-regular ore) and proven massive sulfide mineralization occurring as false and contact mineralization in the study area. 
Table 1. Main acquisition parameters for the Kevitsa 3D seismic survey, 2010.

\section{Survey parameters}

Recording system

No. of receiver lines

No. of shot lines

Receiver line interval

Shot line interval

Maximum source-receiver offset

Survey area

Source

CDP bin size

Spread parameters

Receiver spread array

Receiver (group) interval

Source interval

Recording length

Sampling rate

\section{Receiver and source parameters}

Geophone frequency

Type of base

No. of geophones per set

Total number of receivers

Source pattern

Shot depth

Charge size

No. of shots
Sercel 408 and Seistronix

$$
\begin{gathered}
35 \\
34 \\
70 \mathrm{~m} \\
80 \mathrm{~m} \\
\sim 1700 \mathrm{~m} \\
\sim 9 \mathrm{~km}^{2}
\end{gathered}
$$

VIBSIST and dynamite $10 \mathrm{~m}$ (inline) by $10 \mathrm{~m}$ (crossline)

9 lines $\times 96$ active channels

$15 \mathrm{~m}$

$45 \mathrm{~m}$

$20 \mathrm{~s}$ (VIBSIST) and $3 \mathrm{~s}$ (explosive)

$1 \mathrm{~ms}$ (Sercel 408) and $2 \mathrm{~ms}$ (Seistronix)

$10 \mathrm{~Hz}$

$7.5 \mathrm{~cm}$ spike

Single

6528

Single point/hole

$3 \mathrm{~m}$ (explosive)

$0.5 \mathrm{~kg}$

$\sim 3300$ equipment and $2 \mathrm{~ms}$ for the Seistronix. However, after the decoding, the Seistronix data were resampled to $1 \mathrm{~ms}$ and merged with the Sercel 408 data. In areas with no mechanical source accessibility, an explosive source was used to increase the fold. Nearly 250 explosive sources were fired. The 3D survey area was divided into nine patches (Figure 4a). The swaths were advanced in the following way: When moving north, the receiver lines overlapped the adjacent patch by $50 \%$; while when moving east, shot lines overlapped by $50 \%$. In this manner, a relatively uniform and smooth fold was achieved. Receiver and source spacing were $15 \mathrm{~m}$ and $45 \mathrm{~m}$, respectively. In total 35 receiver lines, each $70 \mathrm{~m}$ apart, and 34 source lines, each $80 \mathrm{~m}$ apart, were used, giving a nominal receiver and source density of about 800 and 400 per square kilometer, respectively (Figure 4a). The seismic data are characterized by a relatively even distribution of offset and azimuth, important for seismic imaging of complex geologic structures in the crystalline environment. Table 1 lists the main acquisition parameters used in the 3D survey.

Source and receiver positions were surveyed using high-precision differential GPS, theodolite and total station. Figure $4 \mathrm{~b}$ shows the elevation map of the study area with the highest elevation (about $290 \mathrm{~m}$ above sea level) in the southern part of the 3D area and the lowest elevations in the central and northern parts (about $210 \mathrm{~m}$ above sea level). The high elevation difference and large variations between the overburden a)

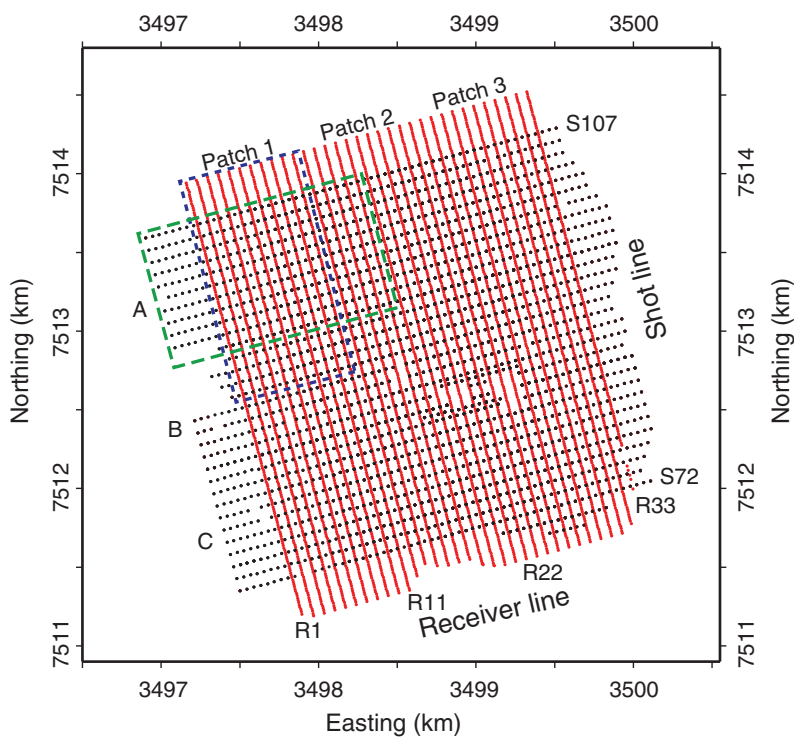

b)

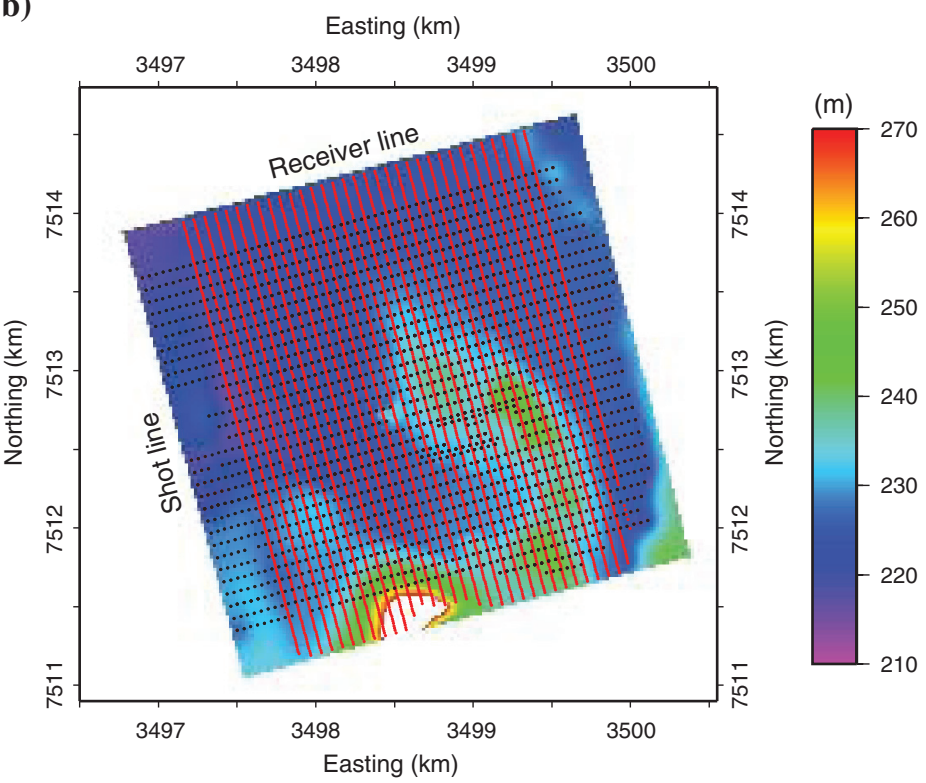

Figure 4. (a) 3D seismic data acquired using nine overlapping (50\%) patches. For example, patch $1 \mathrm{~A}$ (green and blue box) shared 50\% of its source and receiver lines (repeated) into a neighboring patch. (b) Topography map of the study area. Receiver lines (R1, R2 ... etc.) are shown in red and shot lines ( $\mathrm{S} 1, \mathrm{~S} 2, \ldots$ etc.) in black. 
and the underlying bedrock proved to be a challenge when estimating refraction static corrections and also produced complexities in the data due to reverberations in the near surface.

Prior to the 3D survey, a multioffset and multiazimuth VSP (vertical seismic profiling) survey was conducted to provide information about the steeply dipping to subvertical structures that would not otherwise be possible to image by the 3D surface seismic data. This survey was performed in borehole KV28, the deepest borehole at the location of the planned open pit (Figure 1).

\section{D CDP binning}

The CDP bin size along inline $(\Delta x)$ and crossline $(\Delta y)$ directions can be theoretically designed based on the following formula (Yilmaz, 2001)

$$
\Delta x, \Delta y \leq \frac{v_{\text {rms }}}{4 f_{\max } \sin \alpha},
$$

where $r_{\text {rms }}$ is the root-mean square average of velocities down to the target reflector, $f_{\max }$ is the maximum nonaliased frequency required to resolve the target reflector, and $\alpha$ is the structural dip. Based on a maximum useful frequency of $100 \mathrm{~Hz}$ (estimated by studying amplitude spectra), $v_{\text {rms }}$ of $6000-7000 \mathrm{~m} / \mathrm{s}$ (estimated from available sonic logs), and a dip of $60^{\circ}$ (Figure 2), we estimate that a bin size range in the range of 10-20 m should be appropriate for the Kevitsa $3 \mathrm{D}$ data. In practice, other parameters such as survey geometry will affect the design of CDP bin size. For Kevitsa, the seismic data were first binned using 15 by $15 \mathrm{~m}$ bins to quickly evaluate the data quality in the resulting seismic cube. Later, to increase the spatial resolution, the bin size was reduced to 10 by $10 \mathrm{~m}$, giving a nearuniform fold in most parts of the survey, except at its margins (Figure 5a). For the smaller bin size, there is essentially no spatial aliasing in the stacked volumes for frequencies below $100 \mathrm{~Hz}$. Figure $5 b$ and $5 c$ shows the source-receiver offset distribution and the azimuthal coverage for the entire 3D data set. Offsets up to $1.5 \mathrm{~km}$ and a wide azimuth distribution allow imaging of steeply dipping structures in the Kevitsa area. However, steep reflectors at larger depths and at the margin of the 3D survey area require longer offsets or a larger survey area if they are to be imaged.

\section{D DATA PROCESSING AND IMAGING}

Significant effort was made in the decoding of the seismic sweeps. Noisy and low-quality sweeps were rejected during the decoding. The main data acquisition contractor, HiSeis, conducted this part of the data processing to produce standard common-source gathers for conventional processing. For the conventional processing, we used a prestack DMO and poststack migration algorithm. Such a processing strategy has been successful in the past for imaging complex structures in mining areas, and also allows diffractions to be preserved that might originate from faults or smaller bodies (e.g., Adam et al., 2003; Urosevic et al., 2005; Malehmir and Bellefleur, 2009). The key processing steps prior to stacking the data involved: a)

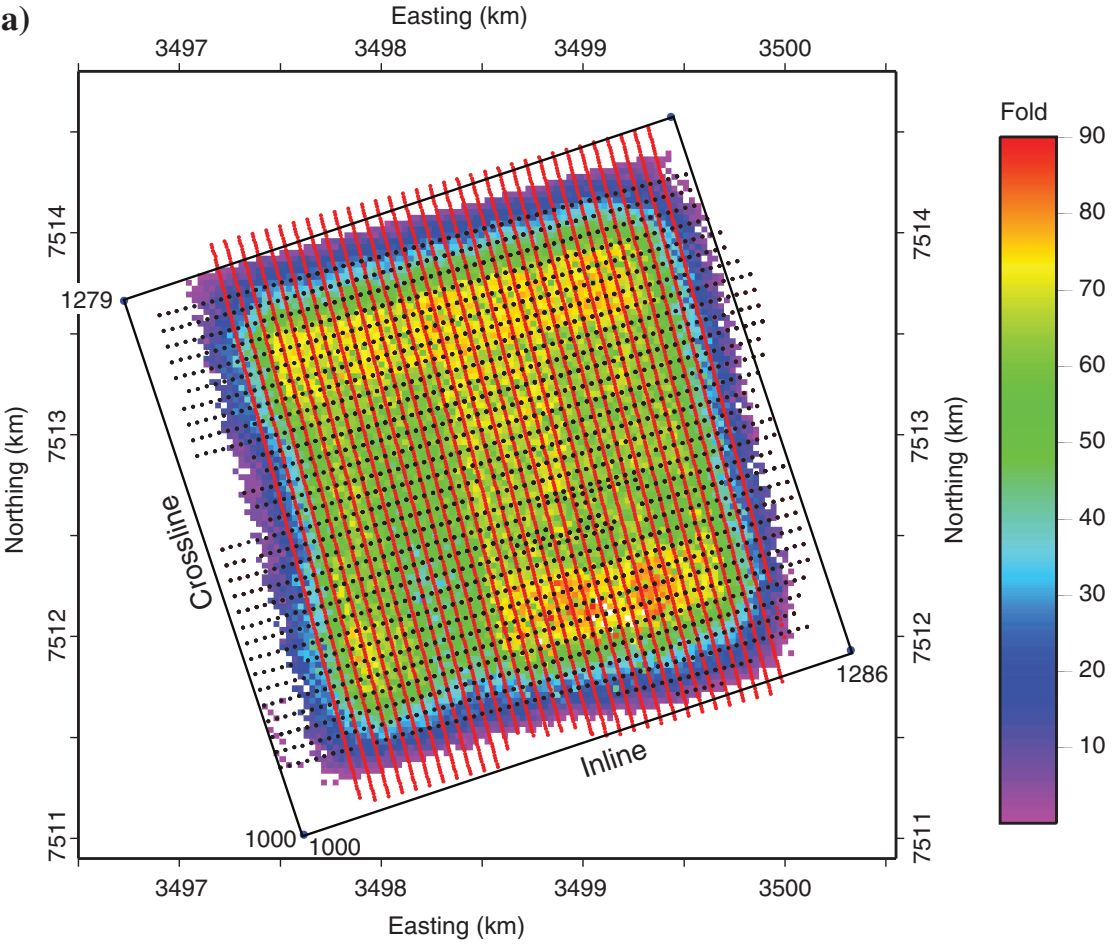

b)

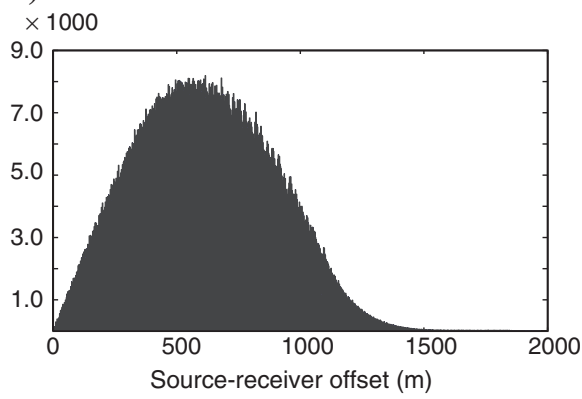

c)

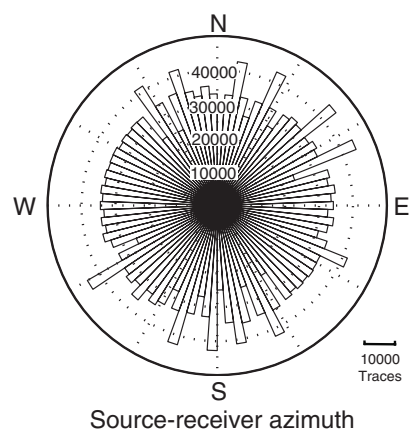

Figure 5. (a) CDP fold coverage calculated from a CDP bin size of 10 by $10 \mathrm{~m}$. The processing area has been chosen to be larger than the actual acquisition area to preserve steeply dipping reflections at the margins of the seismic cube and to reduce migration artifacts. Shown also are the system of CDP inlines and crosslines used for the 3D processing. (b and c) Source-receiver offset distribution and azimuth coverage from the $3 \mathrm{D}$ survey with traces within each $4^{\circ}$ azimuth sector, grouped together for display purposes. 
- Geometry check, trace editing, and removal of bad traces;

- ambient and coherent noise attenuation;

- refraction and residual static corrections;

- velocity analysis; and

- 3D DMO corrections.

In the following subsections, we briefly explain the effects of the various processing steps on the improvement of the seismic data.

\section{Prestack data processing}

Our analysis of the raw shot gathers suggest that the seismic data have generally good-to-excellent quality with strong reflections occasionally observed in some of the raw shot gathers. Figure 6 shows an example shot gather for two receiver lines after various processing steps. Frequency and surface-consistent deconvolution filters were designed to obtain the highest frequency content with useful signal. Surface-consistent spiking deconvolution using a $100 \mathrm{~ms}$ operator helped to improve temporal resolution and to compensate for the effects of variable coupling conditions due to sources and receivers being placed on exposed bedrock or overburden. Obtaining good refraction static corrections was demanding due to the high topographic relief combined with variable near-surface conditions. A careful inspection of a few shot gathers with clear refracted

a)

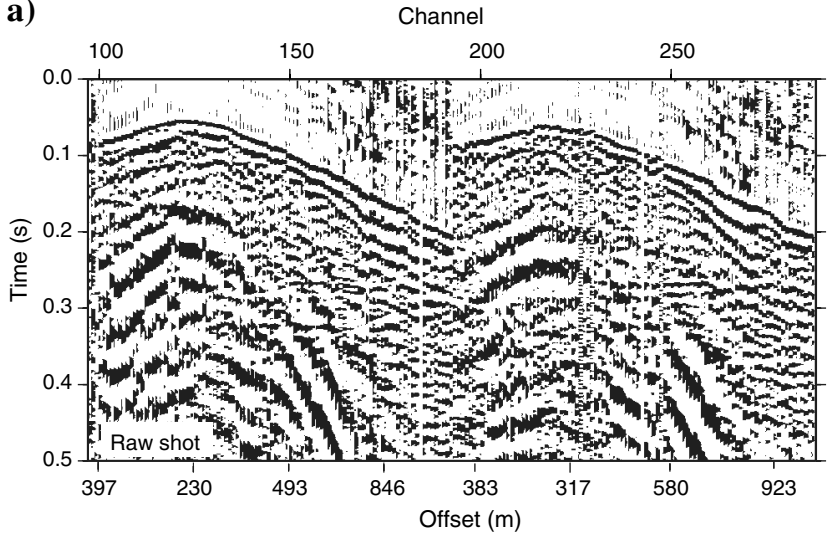

b)

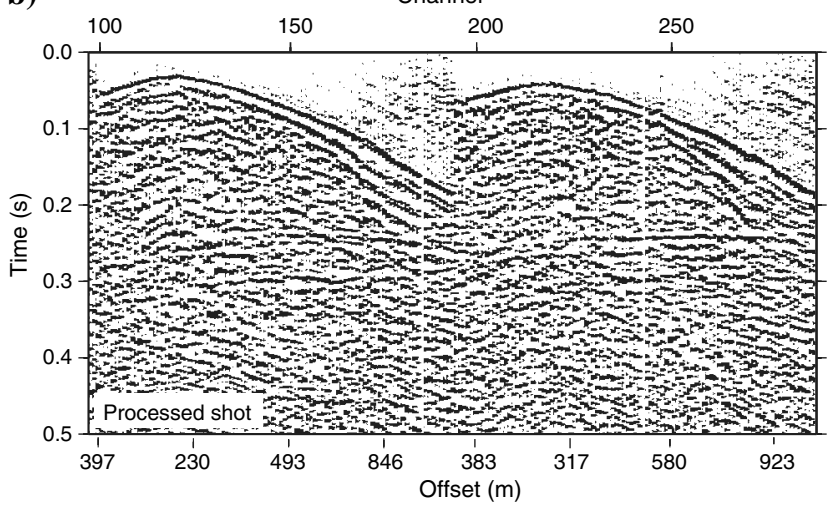

Figure 6. An example shot record (shown for only two receiver lines) (a) before and (b) after various processing steps. Note the increase in the signal quality in (b), and especially the reflections observed between $0.2 \mathrm{~s}$ to $0.3 \mathrm{~s}$. arrivals allowed us to identify two thick (about 80-120 m) lowvelocity zones in the area. The identification of these zones, along with a series of geotechnical boreholes in the vicinity of KV173 (Figure 1), was helpful in examining and validating the estimated refraction static model. The $3 \mathrm{D}$ refraction static corrections were estimated using nearly 2,500,000 automatically picked first arrivals, but manually inspected and corrected where necessary. Resulting source and receiver static corrections, including the effects of large topographic relief, varies from $0 \mathrm{~ms}$ up to about $80 \mathrm{~ms}$. Near-surface traveltime distortions were largely removed after applying refraction static corrections, and the coherency of reflections were markedly improved (Figure 6b).

Figure 7 shows estimated source and receiver statics, as well as estimated bedrock velocity and depth to bedrock in the study area. Although it is not clear why, a thick overburden is associated with the topographic relief observed in the southern part of the 3D data (see Figure 4). The estimated bedrock velocities seem to be reasonable, and generally follow the geologic boundaries observed on the geologic map of the study area (Figure 1). To demonstrate this, we projected the estimated bedrock velocities from the refraction static solution onto the surface geologic map, as shown in Figure 8. It is evident that the high-velocity band with a nearly northwest-southeast strike is related to the olivine pyroxenite unit, which constitutes the host to the Kevitsa deposit. Several low-velocity lithologies at the margins of the 3D survey area are related to the layered stratigraphy observed in the north-northeast (Figure 8). A relatively low velocity lithological unit in the southwestern part of the study area is due to serpentinization of ultramafic rocks, and partly due to deep weathering and fracturing that is known to exist in this part of the study area from geotechnical drillholes and pits. There also are signs of low-velocity zones (e.g., W1 in Figure 8) in the estimated bedrock velocity that indicate northeast-southwest trending faults in the central part of the study area (Figure 8). Therefore, a detailed and advanced seismic tomographic study will be helpful in identifying weak zones (e.g., faults and fracture zones) within the bedrock.

\section{Poststack data processing and imaging}

The stacked volume is highly sensitive to lateral and vertical velocity changes. Data from twelve borehole sonic logs in the study area suggest a large velocity variation in the bedrock, ranging from $5300 \mathrm{~m} / \mathrm{s}$ to as high as $8000 \mathrm{~m} / \mathrm{s}$. To obtain an optimum velocity function, we ran a series of iterative velocity analyses, interactively controlled by inspecting stacked velocity panels. Figure 9a shows an inline section extracted from only an NMO corrected stacked volume. It clearly demonstrates that reflections as shallow as $100 \mathrm{~ms}$ are already visible on the section. To image near-surface structures as shallow as possible, the direct $\mathrm{P}$-wave arrivals were not muted.

Three-dimensional DMO corrections (Deregowski, 1986; Hale, 1991) were applied to obtain a dip-independent stacking velocity. Before the DMO corrections, surface-consistent residual statics were estimated using only NMO corrected gathers. The DMO corrections improved the continuity of dipping reflections and allowed us to image a series of diffraction type signals by increasing the $\mathrm{S} / \mathrm{N}$ and simultaneously imaging crossing seismic events. Figure $9 \mathrm{~b}$ shows the same inline section as Figure 9a, but has been DMO corrected. A comparison between the two sections demonstrates that the DMO corrections have properly restored dips and reduced the 
noise, along with allowing crossing reflections to be imaged. A series of shallow reflections can now be traced nearly to the surface at about crosslines 1050 and 1250 (see Figure 9b).

Perhaps the most difficult part of the data processing was in obtaining a proper velocity function to migrate the data. As mentioned, sonic logs from the study area suggest that velocities are as high as $8000 \mathrm{~m} / \mathrm{s}$, although the central deep borehole (KV28) has a maximum P-wave velocity of about $7400 \mathrm{~m} / \mathrm{s}$ (Figures 10 and 11). To verify this, in a separate attempt, direct downgoing P-wave arrivals from VSP data were used to obtain an independent velocity profile along the borehole (e.g., Schmitt et al., 2007). The VSP data also show high velocities (Figure 10). Based on the VSP data in conjunction with the sonic data a $1 \mathrm{D}$-velocity function that ranges from $6300 \mathrm{~m} / \mathrm{s}$ at the surface to $7300 \mathrm{~m} / \mathrm{s}$ at $300 \mathrm{~ms}$ and increasing to $7450 \mathrm{~m} / \mathrm{s}$ at $1000 \mathrm{~ms}$ was used to migrate the data. Attempts to migrate the data using lower velocities, such as $5800-6500 \mathrm{~m} / \mathrm{s}$, resulted in weaker reflections that tended to cross each other more. After a series of tests using various migration algorithms, we found that phase-shift migration (Gazdag, 1978) provided the best results and allowed the migration of steeply dipping reflections. A $1 \mathrm{D}$-velocity function similar to the one used for the migration was used for the time-to-depth conversion. Two sample migrated and depth-converted sections along inlines 1170 and 1200 are shown in Figure 12.

\section{Assessment and limitations of the resulting image}

There are some potential limitations of the current acquisition geometry and data. The dominant frequency of the seismic data is about $60-80 \mathrm{~Hz}$. Using the Rayleigh quarter-wavelength criterion (Widess, 1973) for an assumed average velocity of $6500 \mathrm{~m} / \mathrm{s}$, the vertical resolution (the ability to resolve the top and bottom of a layer) is about $20-30 \mathrm{~m}$, implying that layers thinner than 20-30 m will not be vertically resolved. However, thin layers (down to 2-3 m) should be detectable if S/Ns and the impedance contrast are sufficiently high, as well as the boundary having sufficient lateral continuity. Using the Fresnel zone criterion (e.g., Sheriff and Geldart, 1995; Yilmaz, 2001), for given depths of $500 \mathrm{~m}$ and $1000 \mathrm{~m}$, the horizontal resolution varies between $300 \mathrm{~m}$ and $450 \mathrm{~m}$, respectively. Objects smaller than the Fresnel zone tend to produce diffractions in an unmigrated stacked cube. Migration tends to collapse the Fresnel zone to approximately the dominant wavelength (Stolt and Benson, 1986) and, in theory, increases the horizontal resolution to at least the dominant wavelength (or half of that). However, the presence of noise and migration-velocity errors affects migration adversely, sometimes degrading the horizontal resolution significantly. It is common with most migration algorithms that reflections contain lower frequencies after migration, and this decrease in frequency is proportional to the reflection dip (Cordsen et al., 2011). In the extreme dip case, a subvertical event appears as a DC bias in the migrated data (Cordsen et al., 2011). b)

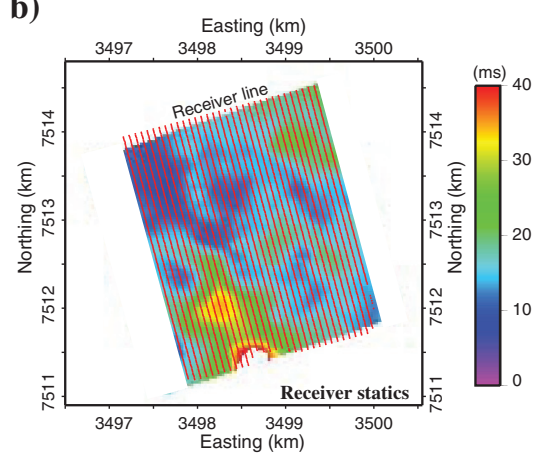

d)

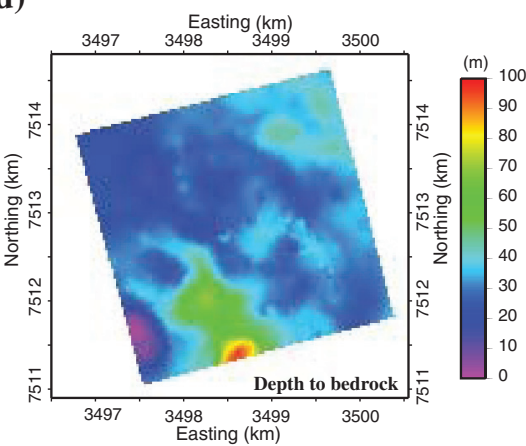

Figure 7. (a) Source and (b) receiver static corrections estimated for the 3D survey. Bedrock (c) velocity and (d) depth to the bedrock used to calculate the statics. Note that refractor velocities in the central part of the study area (c) are as high as $7300 \mathrm{~m} / \mathrm{s}$.

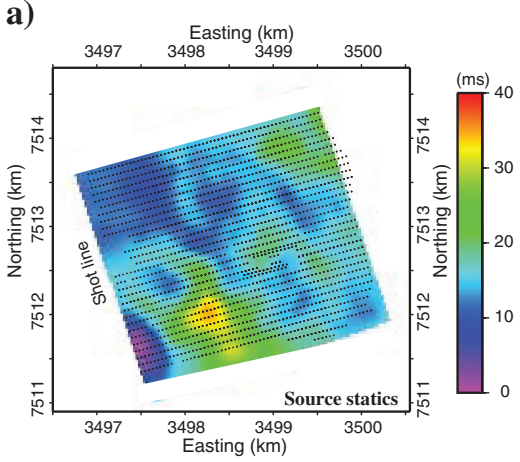

c) Easting $(\mathrm{km})$

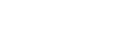

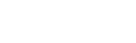
. 

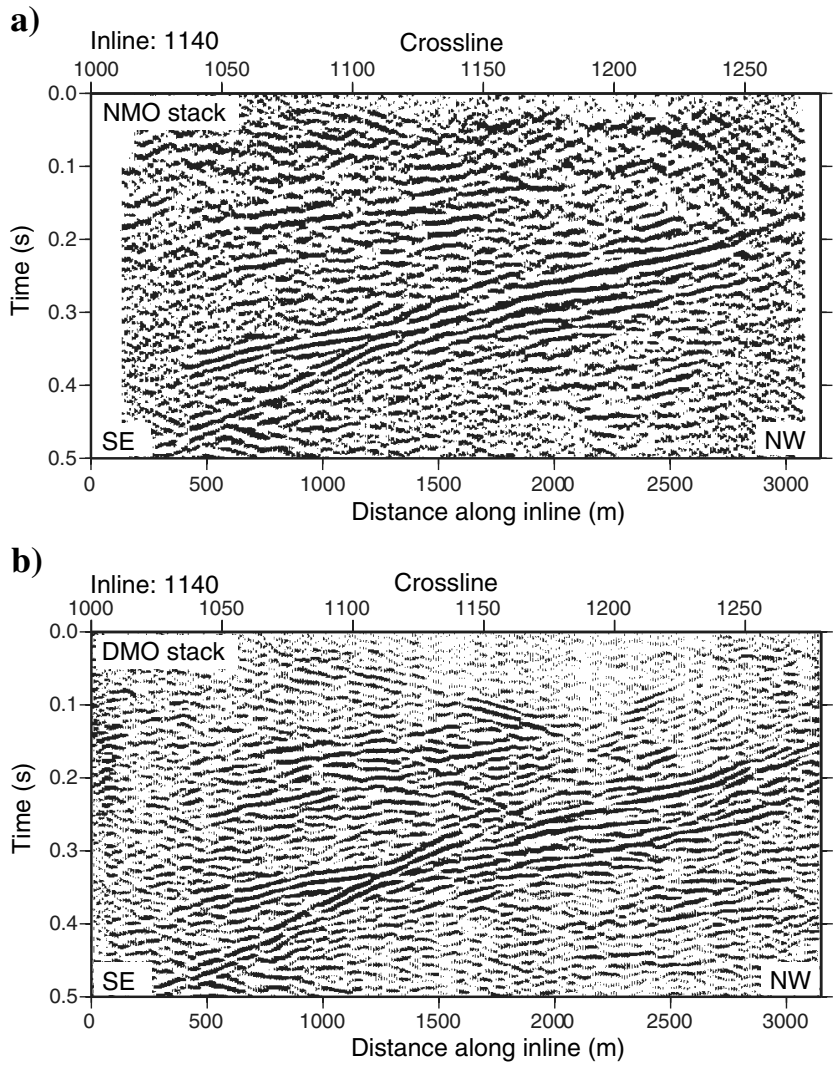

Figure 9. Unmigrated seismic section along inline 1140 obtained using (a) only NMO corrections and (b) using NMO and DMO corrections. Note the increase in the signal quality and the improvements obtained in the shallowest parts $(<100 \mathrm{~ms})$ of the seismic section in (b).
The shallowest reflections observed in the migrated seismic cube are at depths of about $150-200 \mathrm{~m}$. There is a fundamental limitation on the shallowest reflector that can be reasonably well-imaged using the current 3D acquisition geometry. A receiver line spacing of $70 \mathrm{~m}$ and a shot line spacing of $80 \mathrm{~m}$ (Table 1) implies that the largest minimum offset is about $100 \mathrm{~m}$ for the bin that occurs exactly in the middle of two neighboring source and receiver lines, indicating that any reflector shallower than about $100 \mathrm{~m}$ will be difficult to image in the $3 \mathrm{D}$ data set.

Because one of the goals of the 3D survey was to identify areas of interest for deep massive sulfide exploration, diffractor size becomes important. Based on the Rayleigh scattering theory (Korneev and Johnson, 1993), the minimum lateral extent of a detectable sulfide deposit (in this case a diffractor) is $\lambda / 2 \pi$ ( $\lambda$ is the dominant wavelength), which is about $10-20 \mathrm{~m}$ (see also Schmelzbach et al., 2008). However, this detection criterion does not take into account that objects smaller than the Fresnel zone normally lead to scattered energy that diminishes rapidly if it originates at depth (Berryhill, 1977). Because the diffraction amplitudes from massive sulfide deposits generally are very strong (Malehmir and Bellefleur, 2009), this rapid decrease in energy will not necessarily prevent the imaging of them. Therefore, delineating a 10-20 m wide mineralized body at depth is still possible, but will likely depend on noise conditions and the impedance contrast with the surrounding host rock.

\section{RESULTS AND INTEPRETATIONS}

\section{Structural interpretations}

Figure 13a-13d shows a series of depth slices extracted from the migrated seismic cube at 240,340, 440, and $640 \mathrm{~m}$, respectively. Observed and inferred faults are superimposed onto these depth slices. Although reflections at times of about $50 \mathrm{~ms}$ (or about $150 \mathrm{~m}$ ) were observed in the unmigrated seismic cube (e.g., Figure 9), the shallowest reflections observed in the migrated seismic cube are at depths of about $200 \mathrm{~m}$ (e.g., Figure 12). Only a few of the reflections follow the strike of the faults marked in the geologic map of the study area (Figure 13). The remaining reflections crosscut these faults. This lack of correlation between reflections and faults mapped via other techniques indicates that faults appear as discontinuities in the seismic data, rather than reflections.

In terms of reflectivity, we can divide the study area into a series of subvolumes. The zones around the intrusion in the north and in the southeast are highly reflective with long - but disturbed - reflections (Figure 13). Comparison between the observed reflections on the depth slices (Figure 13) and the geologic map of the study area (Figure 1) suggests that these reflections are generated by the interlayered volcanic and sedimentary stratigraphy into which the intrusion was emplaced (e.g., events marked $\mathrm{S}$ in Figure 13). The main lithological units surrounding the intrusion clearly dip toward the south-southwest to west beneath the Kevitsa main intrusion, with a varying dip angle of 
a)

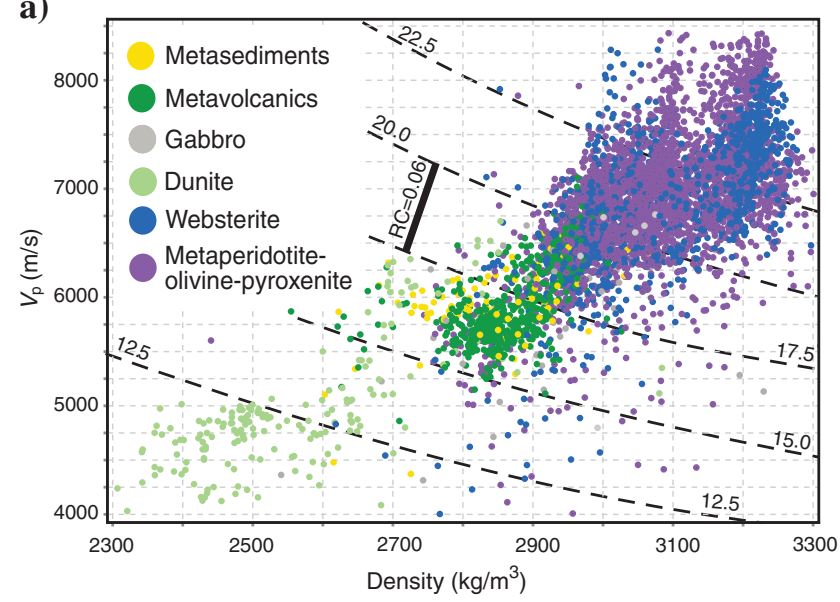

b)
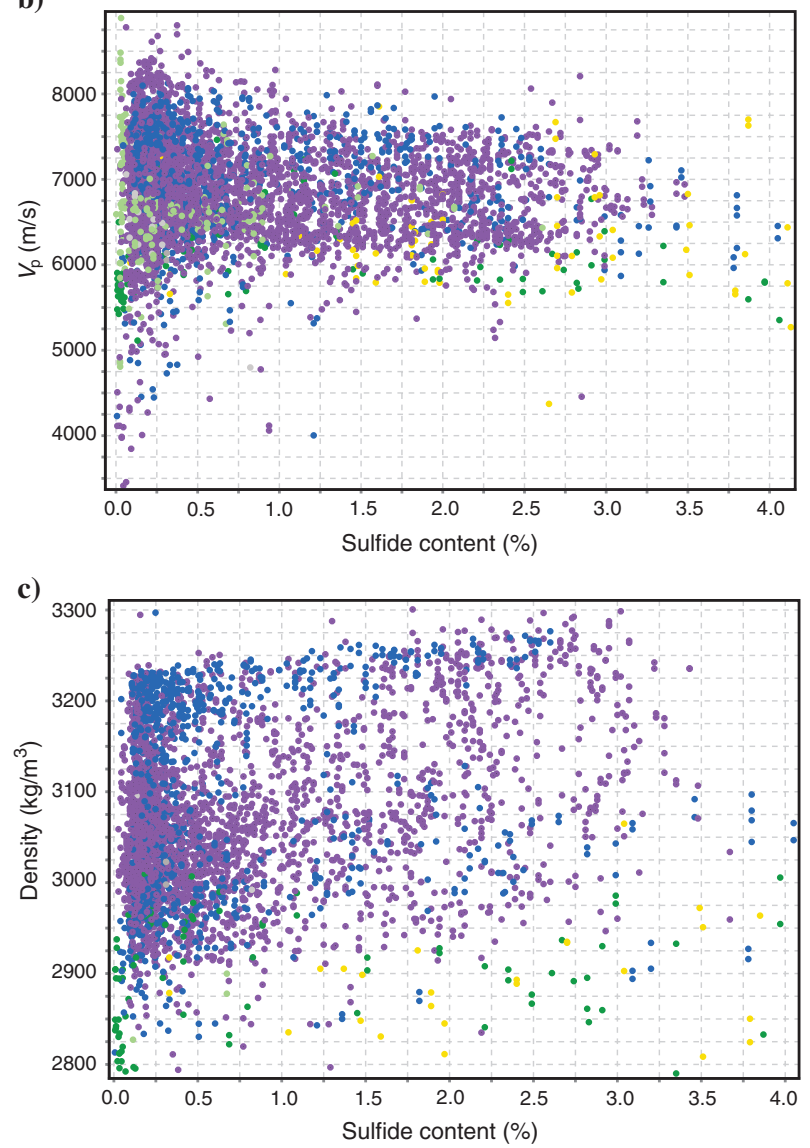

Figure 11. (a) P-wave velocity versus density measured in about 12 deep boreholes in the study area, suggesting clustering of main lithological units. Minimum and maximum velocities are associated with dunite and websterite to olivine-pyroxenite (ore host rock), respectively. Dashed lines represent lines of constant impedance. RC is reflection coefficient between two sets of lines. (b) Velocity versus sulfide content plot and (c) density versus sulfide content plot, showing a positive correlation between sulfide content (mainly pyrrhotite) and density, and a negative correlation with $\mathrm{P}$-wave velocity. $40^{\circ}-60^{\circ}$. The termination of these reflections is a guide to interpreting the base of the Kevitsa intrusion.

The central part of the study area is characterized by a complex pattern of short, relatively gently dipping, but high-amplitude reflections (Figure 13). These reflections (e.g., events marked by $\mathrm{F}$ in Figure 13c and 13d) are spatially confined within the olivine pyroxenite portion of the intrusion, but in a restricted zone within this (Figure 1). They are occasionally in accordance with northeastsouthwest striking faults, especially near the planned Kevitsa open-pit mine. Reflections observed in this area mainly are gently dipping (horizontal to about $30^{\circ}$ ) and occasionally are disturbed. We interpret these reflections to originate from compositional layering within the intrusion, specifically changes in mafic composition that occur in conjunction with grain-size changes and sulfide abundance.

The southern and western parts of the study area, mapped as gabbro and a dunite unit, are seismically transparent with very weak reflectivity (Figures 1 and 13). The dunite is serpentinized, a process that involves significant hydration and consequent destruction of crystalline fabric. However, the gabbro unit is fresh, and also
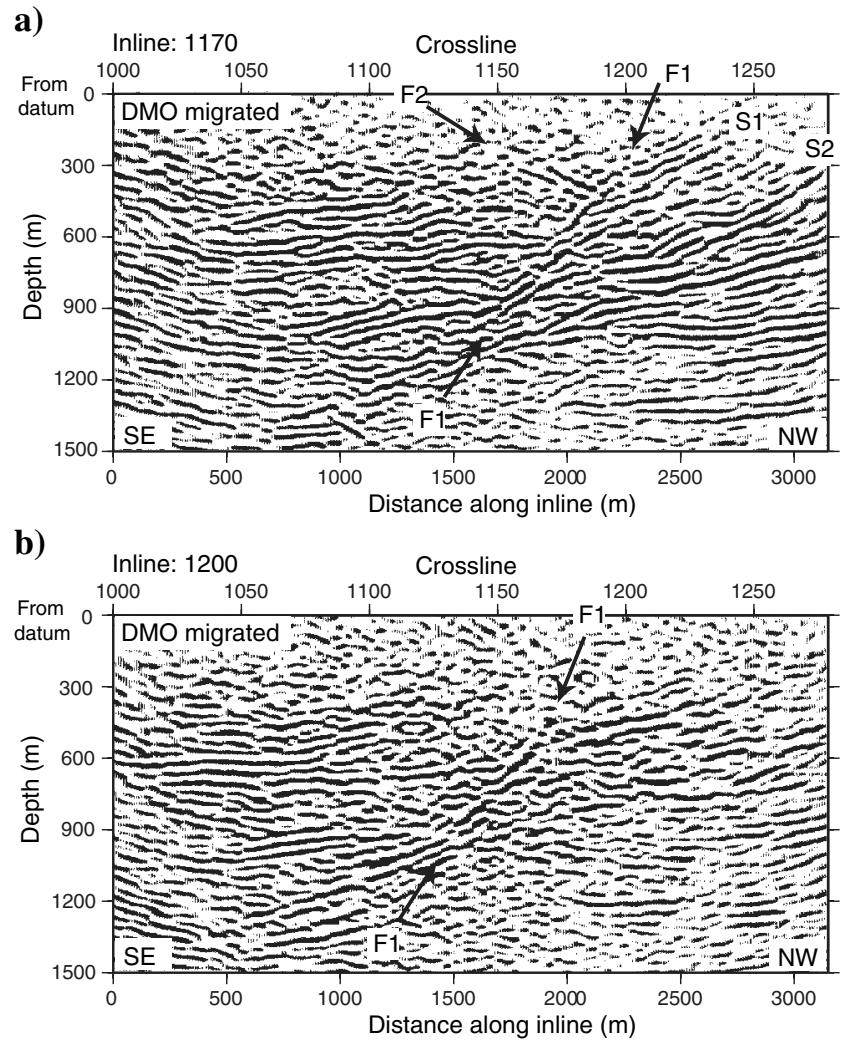

Figure 12. Migrated and time-to-depth converted sections along (a) inline 1170 and (b) 1200 , showing a complex pattern of reflectivity down to a depth of $1500 \mathrm{~m}$ from the processing datum (see Table 2). A large fault system (e.g., F1 and F2) dipping toward the southeast is interpreted where there are onlap structures visible in the southeastern side of the fault. Steeply dipping reflections (e.g., $\mathrm{S} 1$ and S2) observed in the northwestern side of the sections are from the layered-stratigraphy observed in the geologic map of the study area and mark the base of the Kevitsa intrusion at a depth of about $1200-1300 \mathrm{~m}$ at its deepest location. 
provides the low reflectivity expected from a homogeneous crystalline mass. It is more likely that the high amplitude of reflections within the resource area of the olivine pyroxenite is anomalous, and the other igneous units portray normal signatures.

\section{Correlations with VSP data}

To provide better insight into the nature of reflections observed in the seismic volume and their importance for the planned open-pit mine, 3D visualizations of the seismic data (a series of inlines and crosslines) with the surfaces obtained from the VSP data, as well as the planned open-pit geometry, are shown in Figure 14a-14e. Figure 14a shows inline 1167 that crosses the planned open-pit mine (Figure 1). There are numerous reflections in the section. The steeply dipping reflections in the northwestern part of the inline are those generated by the layered stratigraphy from the metasedimentary and volcanic sequence, and those in the central part and southeastern part (relatively gently dipping) are generated within the Kevitsa main intrusion. Careful inspection of the seismic data indicates offset across some of the reflections (Figure 14a and 14c). Correlation with the VSP data suggests that, in many of these instances, these time shifts are associated with steep reflections only observed on the VSP data, which is an indication of a steep or nearvertical fault displacing gently-to-moderately dipping reflectors. With this interpretation in mind, disturbances along gently dipping

Table 2. Principal processing steps applied to the 3D data set.

\begin{tabular}{|c|c|}
\hline Step & Parameters \\
\hline 1. & Read $1.5 \mathrm{~s}$ decoded and resampled to $1 \mathrm{~ms}$ SEG-Y data \\
\hline 2. & Extract and apply geometry (several tests for CDP bin size) \\
\hline 3. & Trace editing \\
\hline 4. & $\begin{array}{l}\text { Pick first breaks: Full offset range, automatic neural network algorithm, but } \\
\text { manually inspected and corrected }\end{array}$ \\
\hline 5. & $\begin{array}{l}\text { Refraction static corrections: Datum } 290 \mathrm{~m} \text {, replacement velocity } \\
\qquad 5500-7400 \mathrm{~m} / \mathrm{s}, v_{0} 1500 \mathrm{~m} / \mathrm{s}\end{array}$ \\
\hline 6. & Geometric-spreading compensation: $v^{2} t$ \\
\hline 7. & Band-pass filtering: $20-30-150-160 \mathrm{~Hz}$ \\
\hline 8. & Surface-consistent deconvolution: Filter $100 \mathrm{~ms}$, gap $10 \mathrm{~ms}$, white noise $0.1 \%$ \\
\hline 9. & Top mute: Only $5 \mathrm{~ms}$ after the first arrivals \\
\hline 10. & Direct shear-wave muting (near-offset) or attenuation (far-offset) \\
\hline 11. & Air-blast attenuation \\
\hline 12. & Trace balance using data window \\
\hline 13. & Velocity analysis (iterative): Every fifth CDP in the inline and the crossline \\
\hline 14. & Residual static corrections (iterative) \\
\hline 15. & Normal moveout corrections (NMO): $50 \%$ stretch mute \\
\hline 16. & 3D dip moveout (DMO) corrections (iteratively link to velocity analysis) \\
\hline 17. & Stack \\
\hline 18. & $f_{x y}$-deconvolution \\
\hline 19. & Trace balance: $0-1000 \mathrm{~ms}$ \\
\hline 20. & Migration: Using smoothed borehole velocities, 3D phase-shift \\
\hline 21. & Time-to-depth conversion: Using smoothed borehole velocities \\
\hline
\end{tabular}

reflections within the main intrusion help to delineate many small faults that would have been otherwise impossible to image by the surface seismic data. A few interpreted faults are observed at the bottom of the planned open-pit mine at a depth of about $400-500 \mathrm{~m}$. This is further confirmed by the VSP data (Figure 14b and $14 \mathrm{~d}$ ). In general, time shifts traced along depth or depth slices correlate much better with previously mapped and interpreted faults than do the reflections themselves. Figure 15 shows a series of nearvertical faults mapped from the 3D seismic cube using this approach.

Comparisons between the surface seismic and VSP data suggest a good correlation between some of the moderately dipping reflections in both data sets. For example, a series of moderately dipping reflections at about $300 \mathrm{~m}$ depth (relative to the sea level) and below that shows excellent correlation with reflections observed on the VSP data (Figure 11) and corresponds to a sequence of highand low-velocity zones somewhat reflected on the estimated velocities from the VSP data and the sonic logs (Figure 11).

\section{Exploration targets}

Many of the more continuous reflections within the Kevitsa intrusion originate from magmatic layering. This layering controls the gross distribution of economic sulfide mineralization, and, therefore, identification of the depth and lateral extent of these layers has a direct implication for exploration to expand the resource. For example, a recent borehole (KV322) drilled in the southeastern part of the intrusion suggests that a series of gently south-southeast dipping reflections observed in the 3D seismic cube (see events marked as M in Figure 15b) is generated by a sequence of mineralized horizons. The mineralization occurs at the base of magmatic layering and contains up to $4 \%$ sulfide mineralization of chalcopyrite and pyrrhotite. Our analysis of petrophysical logs, density, and P-wave velocity, from more than 110,000 data points, from 12 deep boreholes (350-1300 m) indicates that sulfide content up $4 \%$ increases the density by about $200 \mathrm{~kg} / \mathrm{m}^{3}$ (Figure 11c). However, sulfide content does not show a clear relationship with P-wave velocities measured in these boreholes (Figure 11b). Looking at Figure 11b, a negative relationship between the P-wave velocity and sulfide content even can be imagined. Pyrrhotite is a major component of the sulfide mineralogy, and pyrrhotite is known to have a negative effect on seismic velocities (see Salisbury et al., 2000; Malehmir et al., 2012). Therefore, a slight decrease in the seismic velocity where sulfide content increases can be expected in the Kevitsa area. Nevertheless, we expect reflection amplitudes to increase slightly at the contact between magmatic layers due to the larger influence of density. High-amplitude reflections within the main Kevitsa intrusion can be potential targets for enriched sulfide content.

There also are several more discrete, highamplitude reflections present within the main 
intrusion in the central and southeastern parts and in the northern part of the seismic cube in the footwall of the layered stratigraphy (Figure 13d). These reflections are of potential interest as massive sulfide targets in the area. One of these reflections, a bright-spot anomaly, is located in the southeastern part of the seismic cube at about $640 \mathrm{~m}$ depth (Figure 13d) and appears at the margin of the intrusion where potential massive sulfide mineralization is expected to occur (Figure 3). The bright-spot anomaly is also associated with a conductive magnetotelluric anomaly, making it a potential target for drilling. Three-dimensional views using extracted inlines, crosslines, and a depth-slice from the migrated seismic cube highlight the nature of this bright-spot reflection (see event marked as B in Figure 16).

The base of the Kevitsa intrusion clearly is visible in many parts of the seismic cube and, therefore, has been refined using the 3D seismic data and available borehole information (Figures 15 and 16). A reliable interpretation of the base of the intrusion also will be used in the exploration effort, because this provides another target horizon for massive sulfides (Figure 3).

a)

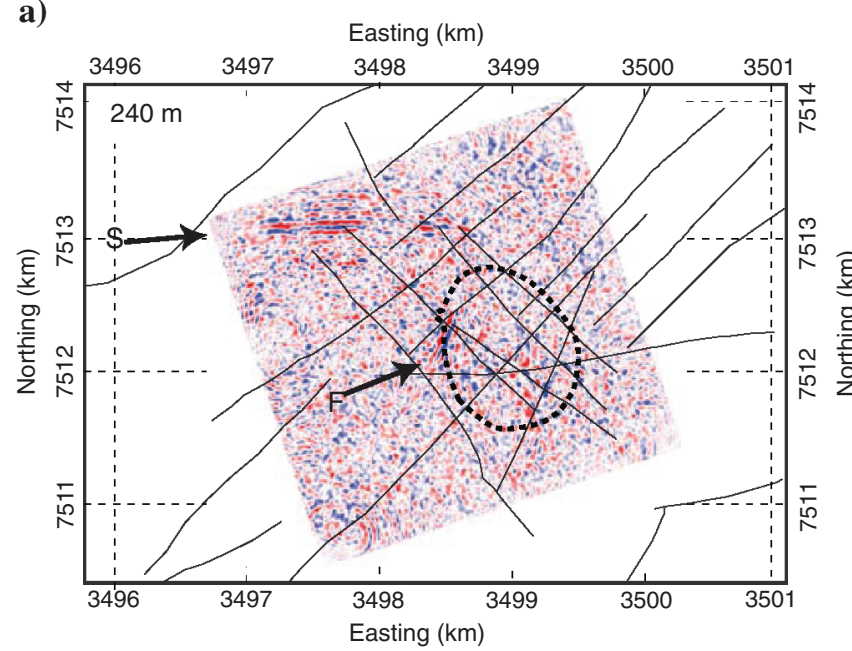

c)

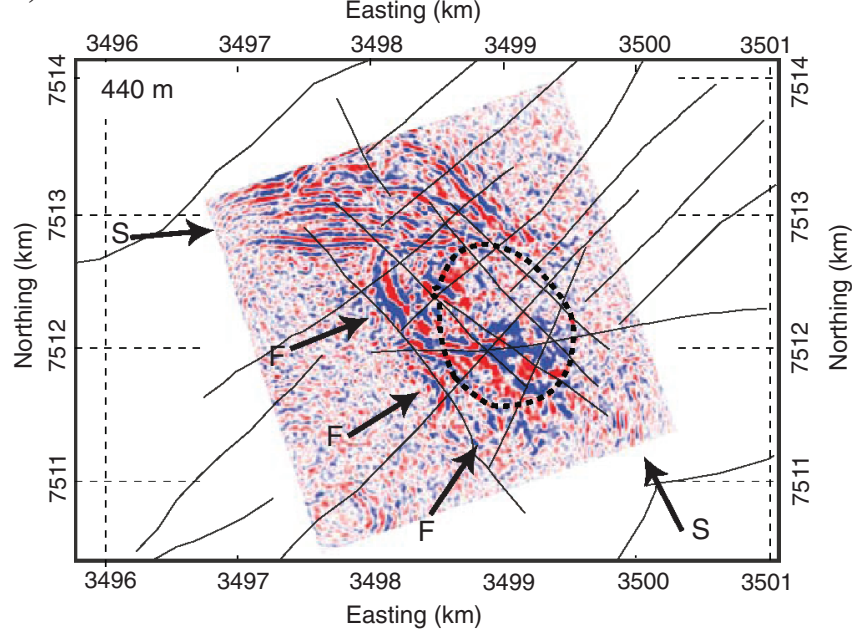

\section{DISCUSSION}

The 3D data set has been challenging to process over this geologically complex area, but contains important information about the internal structures within the main intrusion and the structures surrounding it. The internal compositional layering within the Kevitsa intrusion needs to be considered when interpreting the seismic data, and must be differentiated from fault and/or fracture zones. A late, discordant pulse of ultramafic magma further complicates the geology and the interpretation of the seismic data. The very shallow part of the seismic cube (down to about $200 \mathrm{~m}$ ) is relatively unresolved, which makes direct correlation with the surface geology difficult. However, when correlated with the VSP data, many small, steeply dipping fault systems within the intrusion can be identified in the vicinity of the VSP borehole (KV28) in the 3D data. These fault systems manifest themselves as reflections in the VSP data, but as time shifts along gently dipping reflections in the $3 \mathrm{D}$ data (Figures 13 and 14). At about 500-600 m depth in the planned Kevitsa open-pit mine, a series of dipping reflections is visible

b)

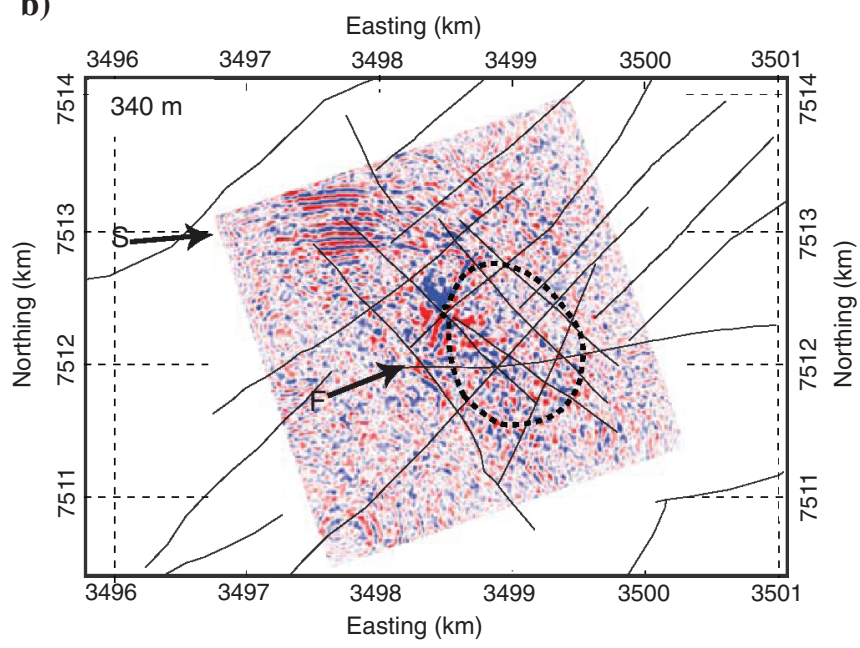

d)

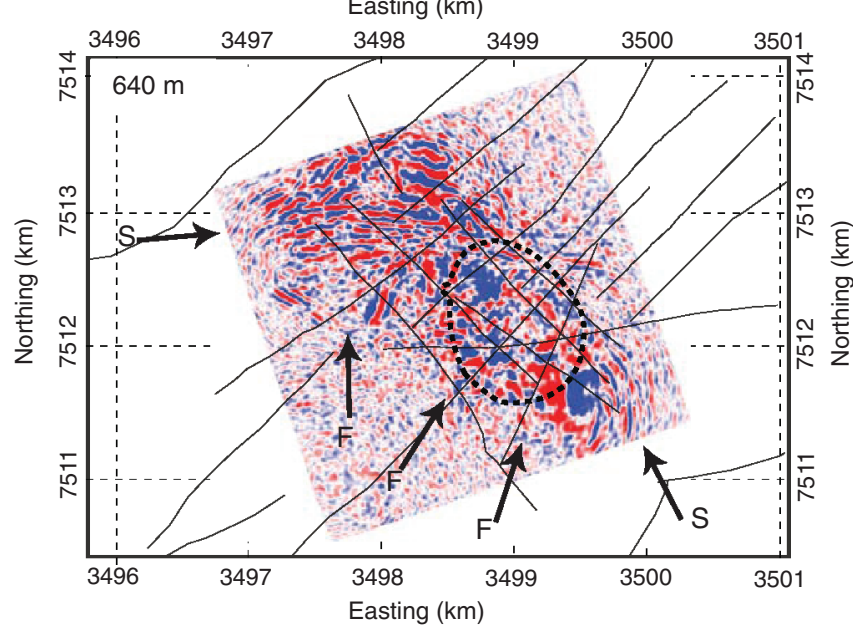

Figure 13. A series of depth-slices at (a) 240, (b) 340, (c) 440, and (d) $640 \mathrm{~m}$ overlain by observed and inferred faults from the study area. Events marked with S show the layered-stratigraphy surrounding the Kevitsa intrusion, and those marked by F show internal structures within the intrusion. The southwestern part of the study area appears seismically transparent. Dashed region shows the area planned for open-pit mining. 
(Figure 14a), which is attributed to magmatic layering. The reflections probably are caused by a combination of compositional and grain size variation, as well as greater sulfide density at the base of each layer. The open pit also appears to be cut by an easterly dipping reflection (Figure 14a and 14b) at a depth of about $300 \mathrm{~m}$. This reflection with a northeast-southwest strike is clearly visible on the depth-slices shown in Figure 13a and 13b. In fact, this reflection is one of the shallowest reflections observed in the migrated seismic cube (Figure 13a) and occurs in the middle of the planned open-pit mine (Figure 1). Although these reflections indicate structural layering within the intrusion, steeper events (Figure 15) will be investigated for the possibility of a structural origin and the risk this could pose to open pit mining. The VSP data also indicate the presence of a few vertical faults (Figure 14b) at the bottom of the open-pit which, together with the surface seismic data, highlight the need for further investigation of the deeper part of the planned mine for any potential faults or weak zones that are important when the mine reaches these depths.

The bedrock velocity estimated for the refraction static model generally correlates well with the bedrock geology (Figure 8). As discussed earlier, there are indications of weak zones (low velocity) in this velocity map, especially within the intrusion (Figure 8). This suggests that advanced tomographic studies using joint VSP and surface seismic data can provide complementary information at the shallow depths (down to about $150 \mathrm{~m}$ ). Prestack time and/or depth migration algorithms also can improve the quality of the seismic cube (e.g., Ogunsuyi et al., 2011). Preliminary tests of prestack time migration algorithms, using the 1D-velocity model shown in Figure 10, indicate an improvement in the seismic image. However, this requires further work and additional velocity data that currently are being collected in existing boreholes in the study area. The large velocity variations observed in the VSP and sonic data (Figures 10 and 11) indicate that a reliable velocity model will be required for any prestack migration method to be successful.

The 3D seismic data clearly have mapped the internal structures within the Kevitsa main intrusion and the layered stratigraphy surrounding it (Figures 13 and 14). The data support the idea that the base of the intrusion, at its center, is at a depth of about $1200 \mathrm{~m}$ and flattens out toward the west and southwest (Figure 15). This is very important for future deep exploration in the area, because it limits the depth extent of any potential mineralization, especially in the

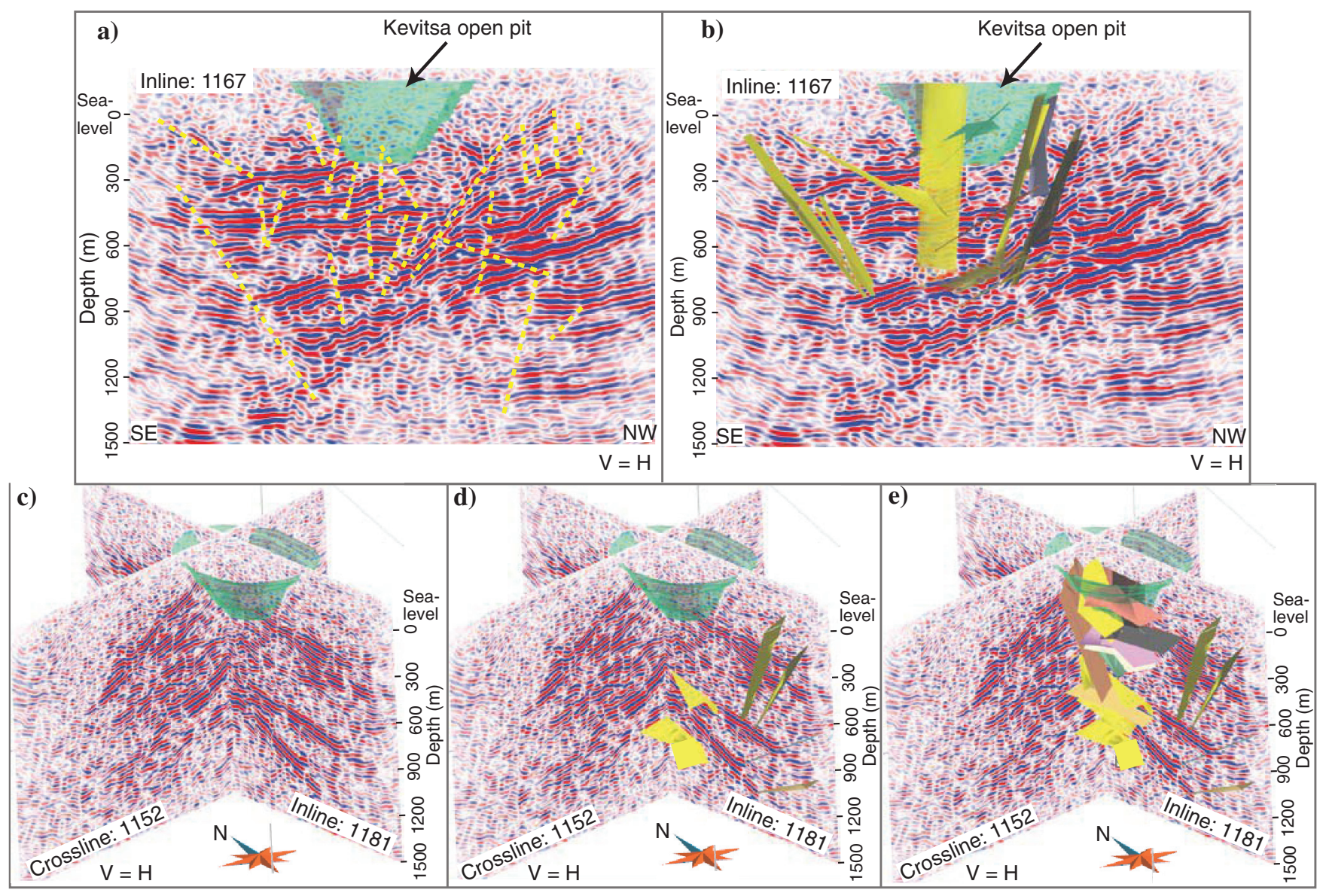

Figure 14. (a) Interpreted seismic section along inline 1167 (b) visualized with surfaces obtained from the VSP data, clearly indicating that time-shifts across some of the reflections are due to the presence of steep faults only manifesting themselves as reflections in the VSP data. Three-dimensional views shown in (c), (d), and (e) further support this interpretation. The light green zone shows the planned open-pit mine that extends down to a depth of about $600 \mathrm{~m}$. A few reflections cross the open-pit at its bottom. The depth is shown relative to sea level with average topography about $240 \mathrm{~m}$ above the sea level (see Figure $4 \mathrm{~b}$ ). 
a)

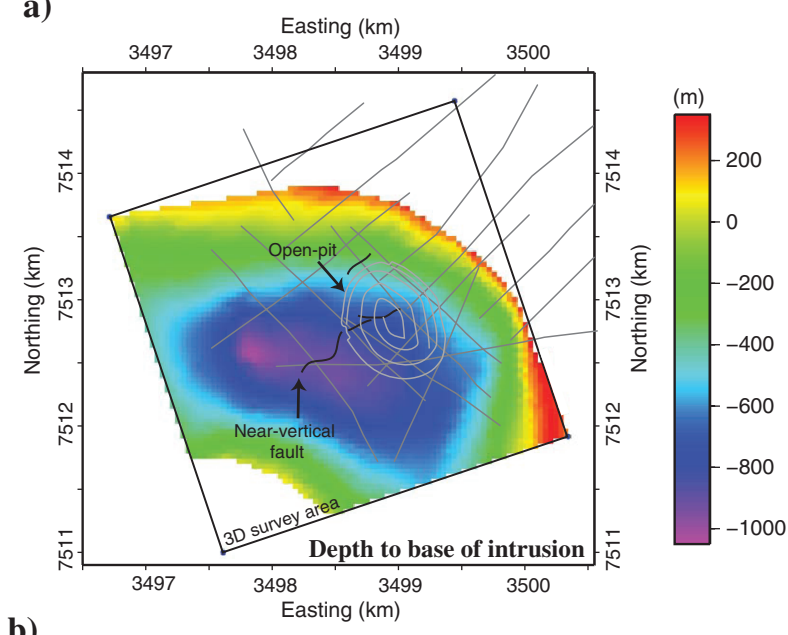

b)

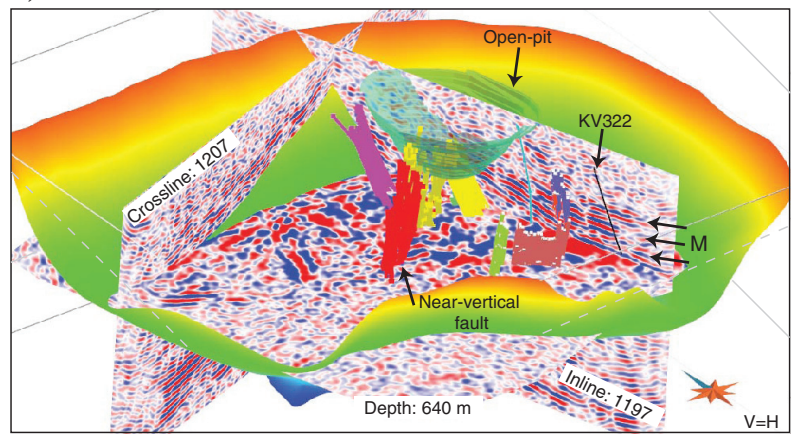

Figure 15. (a) Preliminary interpretation of the depth to the base of the Kevitsa intrusion constrained by the 3D seismic survey and available borehole data in the study area. Solid black lines represent near-vertical faults mapped from the seismic volume. (b) Threedimensional visualization of the seismic data with the planned open-pit mine and the picked near-vertical faults and the base of the Kevitsa intrusion. KV322 is a borehole that intersects a series of sulfide mineralizations and shows a good correlation with reflections observed in the seismic volume (see events marked as $\mathbf{M}$ ).

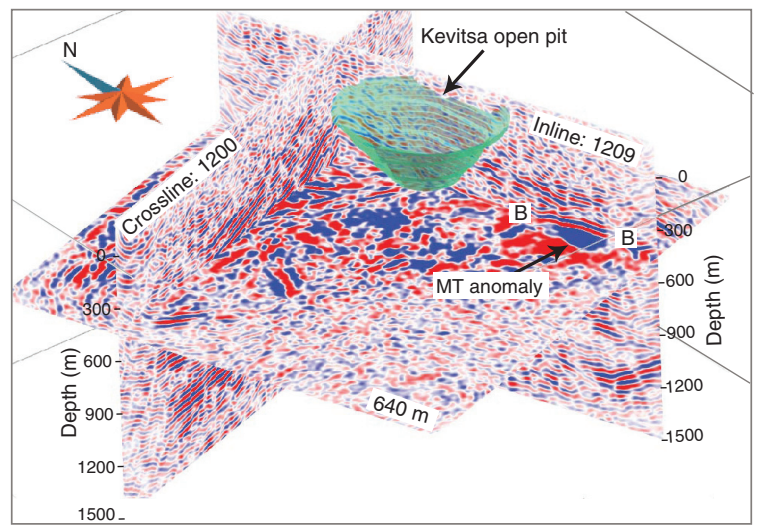

Figure 16. Three-dimensional visualization of inline 1209 and crossline 1200 with the planned open-pit mine showing the depth extent of the Kevitsa intrusion and a bright-spot anomaly (event marked as B) within the intrusion. The bright-spot seismic anomaly at a depth of about $640 \mathrm{~m}$ below the surface is associated with a magnetotelluric (MT) anomaly. Borehole KV322 recently intersected a column of sulfide mineralization at the margin of the bright-spot anomaly; therefore, further exploration success at the Kevitsa deposit was confirmed. eastern part of the study area, and provides a search horizon for one style of massive sulfide mineralization.

\section{CONCLUSIONS}

Three-dimensional reflection seismic data were acquired over the Kevitsa Ni-Cu-PGE orebody for the purposes of mine-planning and deep mineral exploration. Despite challenges encountered during the acquisition due to varying near-surface conditions and large velocity variations in the bedrock, the data processing reveals many reflections, some of which are present within the planned openpit mine. The gently dipping reflections are interpreted to image the magmatic layering within the resource area of the intrusion, which controls economic sulfide distribution. Correlation of the surface data with the VSP data has proven useful for the interpretation of structures at and adjacent to the Kevitsa open-pit mine. Results demonstrate that complex structures and fault systems in the study area can be successfully imaged at depths as shallow as $200-300 \mathrm{~m}$. Steeply dipping faults manifest themselves as time shifts (or phase changes) along gently dipping reflections observed within the $\mathrm{Ke}$ vitsa intrusion. This observation helps to identify areas with complex reflectivity patterns as potential fault and fracture zones, interpretations that will feed into geotechnical planning for the open-pit. Many of these areas are observed in the south and southeastern side of the open pit, as well as at a depth of about 500-600 m inside the open pit.

The Kevitsa seismic data demonstrate the value of this highresolution survey technique to hard rock mining. The surface data have imaged shallow-dipping magmatic layering and the base of the intrusion, and provided discrete high-amplitude targets. Backed up by VSP reflections, we have interpreted numerous faults as terminations or phase changes along reflections. Finally, as mine excavation proceeds, the current interpretation will be put to the ultimate test as each feature in the data is unearthed.

\section{ACKNOWLEDGMENTS}

This work is a joint effort and collaboration between various organizations and people including Uppsala University, Curtin University, the Geological Survey of Finland, and University of Helsinki. HiSeis was responsible for the seismic survey and Vibrometric Oy provided the seismic source and VSP data used in this study. We would like to thank First Quantum Minerals Ltd. for allowing us to publish the preliminary seismic results. GOCAD Consortium and Paradigm are thanked for providing an academic license of GOCAD for 3D visualization and interpretation of the data. GLOBE Claritas ${ }^{\mathrm{TM}}$ under license from the Institute of Geological and Nuclear Sciences Limited, Lower Hutt, New Zealand, was used to process the seismic data. We are grateful for the helpful comments provided by D. Schmitt and an anonymous reviewer, as well as the associate editor B. Milkereit, who helped to improve the clarity of the paper.

\section{REFERENCES}

Adam, E., G. Perron, G. Arnold, L. Matthews, and B. Milkeriet, 2003, 3D seismic imaging for VMS deposit exploration, Matagami, Quebec, in D. W. Eaton, B. Milkereit, and M. H. Salisbury, eds., Hard rock seismic exploration: SEG.

Berryhill, J. R., 1977, Diffraction response for nonzero separation of source and receiver: Geophysics, 42, 1158-1176, doi: 10.1190/1.1440781.

Cheraghi, S., A. Malehmir, and G. Bellefleur, 2011, 2D seismic reflection imaging in the Brunswick no. 6 massive sulphide and iron deposits, Bathurst Mining Camp, Canada: Implications for crustal architecture and 
mineral potential: Tectonophysics, 506, 55-72, doi: 10.1016/j.tecto.2011 .04 .011 .

Cordsen, A., M. Galbraith, and J. Peirce, 2011, Planning 3D seismic surveys, Geophysical development series, no. 6: SEG.

Dehghannejad, M., T. E. Bauer, A. Malehmir, C. Juhlin, and P. Weihed, 2012, Crustal geometry of the central Skellefte district, northern Sweden - Constraints from reflection seismic investigations: Tectonophysics, 524-525, 87-99, doi: 10.1016/j.tecto.2011.12.021.

Dehghannejad, M., C. Juhlin, A. Malehmir, P. Skyttä, and P. Weihed, 2010, Reflection seismic imaging of the upper crust in the Kristineberg mining area, northern Sweden: Journal of Applied Geophysics, 71, 125-136, doi: 10.1016/j.jappgeo.2010.06.002.

Deregowski, S. M., 1986, What is DMO?: First Break, 4, 7-24.

Gazdag, J., 1978, Wave equation migration with the phase-shift method: Geophysics, 43, 1342-1351, doi: 10.1190/1.1440899.

Hale, D., 1991, A nonaliased integral method for dip moveout: Geophysics, 56, 795-805, doi: 10.1190/1.1443097.

Harrison, C., and M. Urosevic, 2009, Towards direct detection of gold bearing formations using seismic methods, St. Ives gold camp, Western Australia: ASEG conference.

Juhlin, C., M. Dehghannejad, B. Lund, A. Malehmir, and G. Pratt, 2010, Reflection seismic imaging of the end-glacial Pärvie Fault system, northern Sweden: Journal of Applied Geophysics, 70, 307-316, doi: 10.1016/j .jappgeo.2009.06.004.

Juhojuntti, N., G. Wood, C. Juhlin, C. O'Dowd, P. Dueck, and C. Cosma, 2012, 3D seismic survey at the Millennium uranium deposit, Saskatchewan, Canada: Mapping depth to basement and imaging post-Athabasca structure near the orebody: Geophysics, this issue.

Koivisto, E., A. Malehmir, P. Heikkinen, S. Heinonen, and I. Kukkonen, 2012, 2D reflection seismic investigations in the Kevitsa Ni-Cu-PGE deposit, northern Finland: Geophysics, this issue.

Korneev, V. A., and L. R. Johanson, 1993, Scattering of elastic waves by spherical inclusions: Part II, Limitations of asymptotic solutions: Geophysical Journal International, 115, 251-263, doi: 10.1111/gii.1993.115.issue-1.

Kukkonen, I. T., P. Heikkinen, S. Heinonen, and J. Laitinen, 2011, Reflection seismics in exploration for mineral deposits: initial results from the HIRE project: Geoscience for Society: 125th anniversary volume. Geological Survey of Finland, special paper 49, 49-58.

Malehmir, A., and G. Bellefleur, 2009, 3D seismic reflection imaging of volcanic-hosted massive sulfide deposits: Insights from reprocessing of the Halfmile Lake data, New Brunswick, Canada: Geophysics, 74, no. 6, B209-B219, doi: 10.1190/1.3230495.

Malehmir, A., and G. Bellefleur, 2010, Reflection seismic imaging and physical properties of base-metal and associated iron deposits in the Bathurst Mining Camp, New Brunswick, Canada: Ore Geology Reviews, 38, 319-333, doi: 10.1016/j.oregeorev.2010.08.002

Malehmir, A., P. Dahlin, E. Lundberg, C. Juhlin, H. Sjöström, and K. Högdahl, 2011, Reflection seismic investigations in the Dannemora area, central Sweden: Insights into the geometry of polyphase deformation zones and magnetite-skarn deposits: Journal of Geophysical Research, 116, B11307, doi: 10.1029/2011JB008643.

Malehmir, A., M. Magnus, M. Lebedev, M. Urosevic, and V. Mikhaltsevitch, 2012, Experimental estimation of velocities and anisotropy of a series of Swedish crystalline rocks and ores: Geophysical Prospecting.

Malehmir, A., C. Schmelzbach, E. Bongajum, G. Bellefleur, C. Juhlin, and A. Tryggvason, 2009b, 3D constraints on a possible deep $>2.5 \mathrm{~km}$ massive sulphide mineralization from 2D crooked-line seismic reflection data in the Kristineberg mining area, northern Sweden: Tectonophysics, 479, 223-240, doi: 10.1016/j.tecto.2009.08.013.

Malehmir, A., H. Thunehed, and A. Tryggvason, 2009a, The Paleoproterozoic Kristineberg mining area, northern Sweden: Results from integrated 3D geophysical and geologic modeling, and implications for targeting ore deposits: Geophysics, 74, no. 1, B9-B22, doi: 10.1190/1.3008053.
Malehmir, A., A. Tryggvason, C. Juhlin, J. Rodriguez-Tablante, and P. Weihed, 2006, Seismic imaging and potential field modeling to delineate structures hosting VHMS deposits in the Skellefte Ore District, northern Sweden: Tectonophysics, 426, 319-334, doi: 10.1016/j.tecto.2006.08 .006 .

Malehmir, A., A. Tryggvason, H. Lickorish, and P. Weihed, 2007, Regional structural profiles in the western part of the Palaeoproterozoic Skellefte Ore District, northern Sweden: Precambrian Research, 159, 1-18, doi: 10 $.1016 /$ j.precamres.2007.04.011.

Milkereit, B., E. K. Berrer, A. R. King, A. H. Watts, B. Roberts, E. Adam, D. W. Eaton, J. Wu, and M. H. Salisbury, 2000, Development of 3D seismic exploration technology for deep nickel-copper deposits-A case history from the Sudbury basin, Canada: Geophysics, 65, 1890-1899, doi: 10 $1190 / 1.1444873$.

Milkereit, B., D. W. Eaton, J. Wu, G. Perron, M. H. Salisbury, E. Berrer, and G. Morrison, 1996, Seismic imaging of massive sulphide deposits: Part II. Reflection seismic profiling: Economic Geology, 91, 829-834, doi: 10 .2113/gsecongeo.91.5.829.

Mutanen, T., 1997, Geology and ore petrology of the Akanvaara and Koitelainen mafic layered intrusions and the Keivitsa-Satovaara layered complex, northern Finland: Report available at: www.arkisto.gsf.fi/bul/BT395 .pdf.

Ogunsuyi, F., and D. R. Schmitt, 2011, Integrating seismic velocity tomograms and seismic imaging: Application to the study of a buried valley, in R. D. Miller, J. D. Bradford, and K. Holliger, eds., Near-surface seismology and ground penetrating radar: SEG, 361-378.

Park, C. B., R. D. Miller, D. W. Steeples, and R. A. Black, 1996, Swept impact seismic technique (SIST): Geophysics, 61, 1789-1803, doi: 10 $.1190 / 1.1444095$.

Pretorius, C. C., M. R. Muller, M. Larroque, and C. Wilkins, 2003, A review of 16 years of hardrock seismics on the Kaapvaal Craton, in D. W. Eaton, B. Milkereit, and M. H. Salisbury, eds., Hardrock seismic exploration: SEG, 247-268

Salisbury, M. H., B. Milkereit, G. Ascough, R. Adair, L. Matthews, D. R. Schmitt, J. Mwenifumbo, D. W. Eaton, and J. Wu, 2000, Physical properties and seismic imaging of massive sulfides: Geophysics, $\mathbf{6 5}, 1882-1889$, doi: $10.1190 / 1.1444872$.

Schmelzbach, C., J. F. Simancas, C. Juhlin, and R. Carbonell, 2008, Seismic reflection imaging over the South Portuguese Zone fold-and-thrust belt, SW Iberia: Journal of Geophysical Research, 113, B08301, doi: 10.1029/ 2007JB005341

Schmitt, D. R., B. Milkereit, T. Karp, C. Scholz, S. Danour, D. Mellieux, and M. Welz, 2007, In situ seismic measurements in borehole LB-08A in the Bosumtwi impact structure, Ghana: Preliminary interpretation: Meteoritics and Planetary Science, 42, 755-768, doi: 10.1111/maps.2007.42 issue-4-5.

Sheriff, R. E., and L. P. Geldart, 1995, Exploration seismology: Cambridge University Press.

Stevenson, F., R. M. A. Higgs, and R. J. Durrheim, 2003, Seismic imaging of precious and base-metal deposits in Southern Africa, in D. W. Eaton, B. Milkereit, and M. H. Salisbury, eds., Hardrock seismic exploration: SEG, 141-156.

Stolt, R. H., and A. K. Benson, 1986, Seismic migration: Theory and practice, handbook of geophysical exploration, 5, Geophysical Press.

Urosevic, M., E. Stolz, and S. Massey, 2005, Seismic exploration of complex mineral deposits - Yilgarn Craton, Western Australia: 67th Annaual International Conference and Exhibition, EAGE, Extended Abstracts, Z-99.

Widess, M. B., 1973, How thin is a thin bed?: Geophysics, 38, 1176-1180, doi: $10.1190 / 1.1440403$

Yilmaz, O., 2001, Seismic data analysis: Processing, inversion and interpretation of seismic data: SEG. 